\title{
Oxygen flush is an effective means to eliminate obscured vision by fogging during intubation using the Airtraq ${ }^{\circledR}$ optical laryngoscope
}

\author{
Fu Shan Xue, MD · Jian-Hua Liu, MD • \\ Yu Jing Yuan, MD $\cdot$ Qiang Wang, MD • \\ Xu Liao, MD
}

Received: 30 August 2010/Accepted: 8 September 2010/Published online: 28 September 2010

(C) Canadian Anesthesiologists' Society 2010

\section{To the Editor,}

The Airtraq ${ }^{\circledR}$ optical laryngoscope (Airtraq) (Prodol Meditec S.A., Vizcaya, Spain) is a new disposable tracheal intubation device with an anatomically-shaped blade that contains two parallel channels, the optical channel and the guiding channel, which accommodates the endotracheal tube (ETT). The image is transmitted to a proximal viewfinder, and the distal viewing lens allows visualization of the larynx and advancement of the ETT. ${ }^{1}$ In addition, the Airtraq has a warming element at the blade tip. According to the manufacturer's manual, the Airtraq light should be turned on at least $30 \mathrm{sec}$ before use to allow heating of the viewing lens and to prevent fogging. ${ }^{2}$ Despite the Airtraq's anti-fog mechanism, we have observed that visualization of the laryngeal inlet can be obscured by fogging on the viewing lens, especially when tracheal intubation time is prolonged in patients with difficult airways. To resolve this issue, and in view of previous experience with another optical laryngoscope $\left(\right.$ Truview $^{\circledR}$ laryngoscope, Truphatek International Ltd, Netanya, Israel $)^{3}$ and the fibreoptic laryngoscopes, ${ }^{4,5}$ we tested the effectiveness of using highflow oxygen to eliminate fogging during laryngoscopy and tracheal intubation using the Airtraq.

After receiving local ethics committee approval and written informed consent, we recruited 321 children (aged three months to $17 \mathrm{yr}$ ) and 283 adults (aged 18-75 yr) into the study. All of the patients were American Society of

Fu Shan Xue, Jian-Hua Liu - contributed equally to this work.

F. S. Xue, MD ( $\square)$ · J.-H. Liu, MD · Y. J. Yuan, MD •

Q. Wang, MD - X. Liao, MD

Chinese Academy of Medical Sciences and Peking Union

Medical College, Beijing, China

e-mail: fruitxue@yahoo.com.cn
Anesthesiologists' physical status I-II patients who were scheduled for elective plastic surgery in our hospital from March 2009 to June 2010. All procedures called for general anesthesia requiring tracheal intubation. Exclusion criteria included patients with a limited mouth opening that precluded insertion of the Airtraq and refusal to participate in the study. All intubations were performed by anesthesiologists who had been trained in the use of an Airtraq in a short-term airway management program and who had performed tracheal intubations using this device in more than 20 patients prior to this study.

Induction and maintenance of anesthesia were not standardized but were left to the discretion of the staff anesthesiologist to use either a propofol or sevofluranebased technique with or without neuromuscular blockade. Before orotracheal intubation, an appropriately-sized ETT was loaded into the guiding channel of the Airtraq, and the ETT tip was positioned at the right side of the viewing lens. When performing nasotracheal intubation, the ETT was inserted via the pre-selected nostril until its tip passed through the posterior naris. The Airtraq was then passed into the patient's airway over the tongue in the midline. Once the Airtraq blade tip was positioned in the vallecula with the glottis in the centre of the viewfinder, the ETT was passed by the glottis and advanced downwards into the trachea. Obscured vision during laryngoscopy and intubation was defined as fogging on the viewing lens that impeded continuous observation for airway structures and ETT advancement. Whenever this problem occurred, an assistant immediately attached the anesthesia circuit to the ETT. By intermittently pushing the oxygen flush valve of an anesthesia machine, a high oxygen flow was transported via the ETT to the distal end of the Airtraq to eliminate the fogging (Figure). The efficiency of de-fogging was assessed using a three-point scale (inefficient $=$ no 
Figure Whenever fogging on the viewing lens occurred during orotracheal (A) and nasotracheal (B) intubations with the Airtraq ${ }^{\circledR}$ optical laryngoscope, the anesthesia circuit was attached to the endotracheal tube. By intermittently pushing the oxygen flush valve, high-flow oxygen was transported via the endotracheal tube to the distal end of the blade to effectively de-fog the viewing device
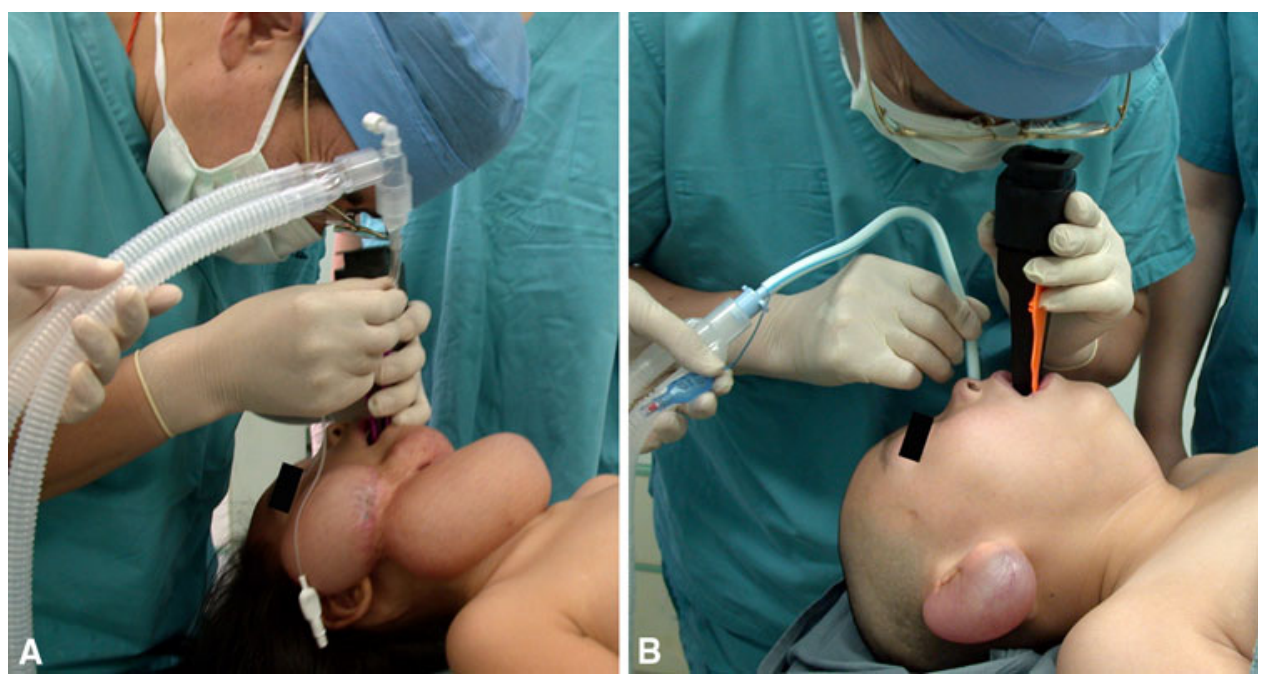

improvement in obscured vision; adequate $=$ fogging partly eliminated; excellent $=$ fogging completely eliminated. In all patients, the tracheal intubation times (defined as the period from initial insertion of the orotracheal Airtraq or nasal ETT to start of ventilation through the ETT) were measured. Statistical analysis was performed using paired Student's $t$ tests and chi square test.

No patient meeting the inclusion criteria declined participation. Of 604 patients, 27 adults and 18 children had known or predicted difficult airways due to micrognathia, a short neck, Mallampati class 3 or 4, and/or limited head and neck movement. Obscured vision occurred in 73 cases (19 adults and 54 children). Incidences of obscured vision during orotracheal and nasotracheal intubations were lower in adults than in children. However, there was no significant difference in the incidence of obscured vision between the two intubation routes either in adults or in children (Table). The obscured vision was adequately improved by pushing the oxygen flush valve two to three times within three to four seconds. An adequate view was achieved in four children and an excellent view reappeared in the remaining 69 patients. Although the ETT was attached to the anesthesia circuit, we did not experience difficulties in advancing the ETT along the guiding channel into the trachea. In all patients, tracheal intubation was completed successfully using the Airtraq, and tracheal intubation times were similar when comparing patients with and without obscured vision (Table). Furthermore, intermittent insufflation with oxygen into the upper airway via the ETT did not result in gastric insufflation because the

Table Incidence of obscured vision during orotracheal and nasotracheal intubations in adult and pediatric patients, and comparison of tracheal intubation times in patients with and without obscured visualization with the Airtraq ${ }^{\circledR}$ optical laryngoscope

\begin{tabular}{|c|c|c|c|}
\hline & & \multicolumn{2}{|c|}{ Incidence of obscured vision $\%$ (number of patients) } \\
\hline \multirow[t]{3}{*}{ Adults } & Orotracheal intubation & \multicolumn{2}{|l|}{$7.1(12 / 170)$} \\
\hline & Nasotracheal intubation & \multicolumn{2}{|l|}{$6.2(7 / 113)$} \\
\hline & Total & \multicolumn{2}{|l|}{$6.7(19 / 283)$} \\
\hline \multirow[t]{5}{*}{ Children } & Orotracheal intubation & \multicolumn{2}{|l|}{$16.3(40 / 245)^{*}$} \\
\hline & Nasotracheal intubation & \multicolumn{2}{|l|}{$18.4(14 / 76)^{*}$} \\
\hline & Total & \multicolumn{2}{|l|}{$16.8(54 / 321)^{*}$} \\
\hline & & \multicolumn{2}{|c|}{ Tracheal intubation times means $(s) \pm S D$} \\
\hline & & Without obscured vision & With obscured vision \\
\hline \multirow[t]{2}{*}{ Adults } & Orotracheal intubation & $14.5 \pm 8.5(n=158)$ & $16.5 \pm 9.1(n=12)$ \\
\hline & Nasotracheal intubation & $20.2 \pm 7.6(n=106)$ & $22.4 \pm 8.5(n=7)$ \\
\hline \multirow[t]{2}{*}{ Children } & Orotracheal intubation & $13.7 \pm 7.9(n=205)$ & $15.8 \pm 8.6(n=40)$ \\
\hline & Nasotracheal intubation & $18.2 \pm 7.6(n=62)$ & $21.3 \pm 7.9(n=14)$ \\
\hline
\end{tabular}

$* P<0.05$ compared with adults. $\mathrm{SD}=$ standard deviation 
oral cavity and nasal passage were open when the Airtraq was in place.

Our results suggest that the Airtraq has potential as a useful device for orotracheal and nasotracheal intubations in patients with both uncomplicated and difficult airways; however, fogging can obscure vision on the viewing lens and may limit clinical applications. To facilitate tracheal intubation, insufflation of high-flow oxygen via the ETT is a simple and effective means to obtain optimal viewing with the Airtraq device.

Competing interests The Airtraq ${ }^{\circledR}$ laryngoscope used in this observational study was purchased from the manufacturers. No author received financial support for this study and there are no potential conflicts of interest related to this work.

\section{References}

1. Maharaj CH, Ni Chonghaile M, Higgins BD, Harte BH, Laffey JG. Tracheal intubation by inexperienced medical residents using the Airtraq and Macintosh laryngoscopes-a manikin study. Am J Emerg Med 2006; 24: 769-74.
2. Neustein SM. Use of the Airtraq laryngoscope. Anesthesiology 2007; 107: 674.

3. Malik MA, Maharaj CH, Harte BH, Laffey JG. Comparison of Macintosh, Truview EVO2, Glidescope, and Airwayscope laryngoscope use in patients with cervical spine immobilization. Br J Anaesth 2008; 101: 723-30.

4. Piepho T, Thierbach AR, Gobler SM, Maybauer MO, Werner C. Comparison of two different techniques of fibreoptic intubation. Eur J Anaesthesiol 2009; 26: 328-32.

5. Xue FS, Zhang YM, Liao X, Xu YC. Measures to decrease failed intubation with the pediatric Bonfils fiberscope by the obscure vision. Pediatr Anesth 2009; 19: 419-21.

6. Liao X, Xue FS, Zhang YM. Tracheal intubation using the Bonfils intubation fibrescope in patients with a difficult airway. Can J Anesth 2008; 55: 655-6. 